\title{
Healthy apple snack developed using microwaves
}

\section{Fartdinov, D..$^{\text {a }}$ Comaposada, J. ${ }^{\text {a }}$ Muñoz, I. ${ }^{\text {a }}$; De Wit, N. ${ }^{\text {; }}$ Gou, P.a.$_{\text {Guàrdia, M. D. }}^{\text {a* }^{*}}$}

${ }^{\text {a }}$ IRTA-Food Technology. E-17121 Monells, Girona, Spain.

${ }^{\mathrm{b}}$ Faculty of Life Sciences. University of Wageningen, Wageningen, The Netherlands.

*E-mail of the corresponding author: mariadolors.guardia@ irta.cat

\begin{abstract}
The $M W$ heating at early or at final stage of drying process to obtain a crispy apple snack was studied. The effect of MW power and time of application was also evaluated on colour, texture, physico-chemical and sensory properties. Apple snack obtained with the MW heating (7.5 min at $3.000 \mathrm{~W})$ at early stage after an osmotic pre-treatment resulted in apple slices more porous and with better sensory attributes than if it is applied at later stage of drying.
\end{abstract}

Keywords: apple; snack; drying; microwaves 


\section{Introduction}

One of the main barriers for fruit consumption is convenience. The application of new preservation technologies allows developing new food concepts, such as snacks, which can fulfil the consumer demand of convenience and, as a result, increase fruit consumption.

Apple drying has been studied extensively during the few past decades [1-4] by means of processes which combine an osmotic treatment and a conventional convective drying. Results were acceptable and a stable shelf-life over 6 months [5] has been reached. However, these processes are very time consuming $(4.5 \mathrm{~h})$. Microwave drying (MW) combined with other drying conventional methods could decrease the processing time [6]. Therefore, including MW in the drying process, could be useful in order to save time and energy and, in addition, improve the snack quality. It is still not clear which is the best time to apply MW to obtain a crispy snack. Some authors [7] assert that MW heating applied at the earlier stage of drying leads to more porous product, whereas others [8,9] indicate that this parameter is enhanced when the MW heating is carried out at the final stage of drying process.

The present work aimed to compare the effect of the MW heating at early or at final stages of drying on the colour, texture, physico-chemical and sensory properties of an apple snack.

\section{Materials and Methods}

\subsection{Sample preparation}

Golden Delicious apples and apple juice from local suppliers were stored at $4^{\circ} \mathrm{C}$. Quality of the raw material was relatively stable since all the experiments were completed in 1-2 weeks. Apples were washed and manualy sliced at $4 \pm 0.3 \mathrm{~mm}$-thickness with a calibrated cork borer. Sugar content of the apple juice was $12.2 \pm 0.2^{\circ}$ Brix.

\subsection{Apple snack processes}

The preparation of the apple snack consisted in a three stage process. The stage was an osmotic pre-treatment $(\mathrm{O})$ followed by a combined treatment of $\mathrm{MW} /$ Convective drying $(\mathrm{C})$ or C/MW. Different MW power ratios were applied to the product (Table 1).

Table 1. Treatments used to develop the apple snack

\begin{tabular}{cccccc}
\hline \multirow{2}{*}{ Process } & $\begin{array}{c}\text { Drying } \\
\text { Stage 1 }\end{array}$ & $\begin{array}{c}\text { Drying } \\
\text { Stage 2 }\end{array}$ & $\begin{array}{c}\text { MW power ratio } \\
(\mathbf{W} / \mathbf{g})\end{array}$ & $\begin{array}{c}\text { MW power } \\
(\mathbf{k W})\end{array}$ & $\begin{array}{c}\text { MW time } \\
(\mathbf{s})\end{array}$ \\
\hline 1 & MW & C & 2.98 & 3.0 & 452 \\
2 & MW & C & 5.56 & 6.0 & 226 \\
3 & C & MW & 18.77 & 3.0 & 452 \\
4 & C & MW & 40.76 & 6.0 & 226 \\
\hline
\end{tabular}




\section{Osmotic pre-treatment (O)}

Apple slices were dipped in apple juice at $4^{\circ} \mathrm{C}$ in a solution ratio $1: 2(\mathrm{w} / \mathrm{w})$ for $60 \mathrm{~min}$. Then, moisture content $(\mathrm{MC})$ and water activity $\left(\mathrm{a}_{\mathrm{w}}\right)$ were measured. After the osmotic treatment and before starting the drying process, samples were blotted by gravity to remove the excess of water.

\section{Microwave drying (MW)}

MW heating was carried out in an industrial MW continuous tunnel (F00003801A, MES Technologies, France; see Fig.1). Apple slices were placed onto the conveyor belt (single layer) at $0.45 \mathrm{~m} / \mathrm{min}$ at $25^{\circ} \mathrm{C}$. Table 1 shows the MW power ratio applied.

\section{Convective drying $(C)$}

Convective drying (C) was carried out in a conventional dryier placing the apple slices in a single layer onto a grid. Samples were dried at $107 \pm 3^{\circ} \mathrm{C}, \mathrm{RH}<3 \%$ and $1.5 \mathrm{~m} / \mathrm{s}$ air velocity for $60 \mathrm{~min}$. Between drying stages 1 and 2 and at the end of the process, samples were cooled down during $5 \mathrm{~min}$ at $15 \pm 3^{\circ} \mathrm{C}$.

\subsection{Parameters recorded or analysed}

\section{Temperature (T)}

Temperature was measured with optic fiber probes (FOT-L-NS-484B,FISO Technologies, Canada). The probe was placed inside the apple slice, $15 \mathrm{~mm}$ from the surface and connected to a data logger (TMI, FISO Technologies, Canada).

\section{Water activity $\left(\mathrm{a}_{\mathrm{w}}\right)$}

Water activity $\left(\mathrm{a}_{\mathrm{w}}\right)$ was measured at $25^{\circ} \mathrm{C}$ with an AquaLab Series 3 instrument (Lab-Ferrer, Cervera, Spain). Three replicates per treatment were carried out.

\section{Moisture content (MC)}

Moisture content (MC) of the samples was determined by drying until reaching constant weight (Association of Official Analytical Chemists [AOAC], 1990). Three replicates per treatment were carried out.

\section{Density and porosity}

True density of dried apple slices was measured by means of a pycnometer using the volumetric displacement method [10]. The apparent density was measured using the solid displacement method [11] and a graduated burette of $100 \pm 0.5 \mathrm{ml}$. Porosity $(\varepsilon)$, was calculated according to Eq.1: 


$$
\varepsilon=1-\frac{\rho_{b}}{\rho_{s}}
$$

where $\rho_{b}$ and $\rho_{s}$ are the bulk density and solid density expressed in $\mathrm{g} / \mathrm{cm}^{3}$. Three replicates per treatment were carried out.

\section{Instrumental Colour measurements}

Instrumental colour measurements were carried out with the colorimeter Konica Minolta Chroma Meter CR-400 ( AQUATEKNICA, S.A.,Valencia,Spain) with illuminant D65 (2º standard observer ans specular component included) in the CIE-Lab space: L* (lightness), a* (redness) and $\mathrm{b}^{*}$ (yellowness) (Commission Internationale de l'Éclairage [CIE], 1976). Colour measurements were performed on 8 samples per treatment and averaging 3 readings.

\section{Instrumental Texture measurements}

Texture was measured using a TA.XT plus Texture Analyzer (Stable Micro System Ltd.,Godalming, UK) for force/displacement with a $5 \mathrm{~kg}$ load cell, using a spherical probe (P/0.25). Samples were placed onto the HDP/CFS (Crisp Fracture Support Rig and corresponding platform, SMS). Test settings were: speed $7 \mathrm{~mm} / \mathrm{s}$, trigger force $0.049 \mathrm{~N}$, probe travel distance $5 \mathrm{~mm}$. A force-time curve was recorded and maximum peak Force (N) was measured. Ten measurements per treatment were carried out.

\section{Sensory analysis}

Six trained assessors [12] undertook the sensory analysis on dried apple slices. The generation and selection of the descriptors was previously carried out by 2 open discussion sessions. Product was evaluated for appearance, odour, flavour/taste, texture and overall sensory quality. A non-structured scoring scale [13] was used, where 0 means absence of the descriptor and 10 means very high intensity of the descriptor. Two tasting sessions were carried out. Samples were coded with three random numbers and were presented to the assessors balancing the first-order and carry-over effects.

\section{Statistical analysis}

The analyses of variance were performed with the General Linear Model (GLM) procedure of the SAS statistical package (Statistical Analysis System [SAS], 9.4). The model for the physicochemical, instrumental colour, instrumental texture parameters and sensory attributes included the treatment as fixed effect. Differences among means were tested with the Tukey test $(\mathrm{p}<0.05)$. 


\section{Results and discussion}

Apples used in the present study had $83.3 \pm 0.3 \%$ moisture content and $5.7 \pm 0.8 \mathrm{~N}$ firmness. The osmotic pre-treatment was studied only in terms of moisture gain; samples absorved apple juice up to a moisture of $85.1 \pm 0.04 \%$.

\section{Moisture content (MC), water activity $\left(\mathrm{a}_{\mathrm{w}}\right)$ and porosity $(\varepsilon)$}

Table 2 shows that the application of MW treatment at the 1st drying stage (processes 1 and 2) reduced the $\mathrm{MC}$ by about $5 \%$, while the convective drying (2nd drying stage) reduced the MC by about $70 \%$. No significant differences were observed in MC and $\mathrm{a}_{\mathrm{w}}$ between processes 1 and 2, therefore, the power ratio applied did not affect them. Slice porosity $(\varepsilon)$ in process 2 was lower than in process 1 . This could be explained by the temperature reached by the slices through the MW heating. In process 2 , slices reached up to $68{ }^{\circ} \mathrm{C}$, while in process 1 , up to $55^{\circ} \mathrm{C}$. Some studies reported that high temperature causes damage in the porous structure and, as a consequence, porosity decreases [14].

Table 2. Moisture content (MC), Water activity (aw) and porosity (E) of the apple snack samples

\begin{tabular}{ccccccc}
\hline Sampling time & \multirow{2}{*}{ Variable } & RMSE & \multicolumn{4}{c}{ Process } \\
\cline { 3 - 7 } & & & 1 & 2 & 3 & 4 \\
\hline \multirow{2}{*}{ After stage 1 } & MC [\%] & 0.897 & $79.15^{\mathrm{a}}$ & $80.32^{\mathrm{a}}$ & $9.44^{\mathrm{b}}$ & $8.77^{\mathrm{b}}$ \\
& $\mathrm{a}_{\mathrm{w}}[-]$ & 0.0091 & $0.980^{\mathrm{a}}$ & $0.979^{\mathrm{a}}$ & $0.191^{\mathrm{b}}$ & $0.198^{\mathrm{b}}$ \\
& & & & & & \\
After Stage 2 & MC [\%] & 0.796 & $7.31^{\mathrm{b}}$ & $7.40^{\mathrm{b}}$ & $9.91^{\mathrm{a}}$ & $9.05^{\mathrm{a}}$ \\
& $\mathrm{a}_{\mathrm{w}}[-]$ & 0.0022 & $0.165^{\mathrm{b}}$ & $0.167^{\mathrm{b}}$ & $0.221^{\mathrm{a}}$ & $0.201^{\mathrm{a}}$ \\
& $\varepsilon[-]$ & 0.0084 & $0.545^{\mathrm{a}}$ & $0.423^{\mathrm{b}}$ & $0.494^{\mathrm{ab}}$ & $0.520^{\mathrm{a}}$ \\
\hline
\end{tabular}

${ }^{\mathrm{a} b}$ Means without a common superscript in a row are significantly different $(\mathrm{p}<0.05)$; RMSE: Root mean standard error; Process 1: MW (7.5 min at $3000 \mathrm{~W})+\mathrm{C}$; Process 2: MW(3.75 min at $6000 \mathrm{~W})+\mathrm{C}$; Process 3: C + MW (7.5 min at $3000 \mathrm{~W})$; Process 4: C + MW (3.75 min at $6000 \mathrm{~W})$.

When convective drying was applied at the 1st drying stage (processes 3 and 4), the MC was reduced by about $76 \%$ whereas the MW application at the 2nd stage of drying could not reduce it. The power ratio applied did not significantly affect the $\mathrm{MC}$ and $\mathrm{a}_{\mathrm{w}}$. No significant differences in porosity $(\varepsilon)$ were observed between processes 3 and 4 .

Treatments with the MW application at the 1st stage resulted in a significant reduction of both MC and $\mathrm{a}_{\mathrm{w}}$ at the end of the process. Therefore, the MW application at earlier drying stage is more efficient than the MW application at later drying stage under the experimental conditions of the present trial. 


\section{Colour and instrumental texture parameters}

The driest samples (process 1 and 2) showed the lowest lightness $\left(\mathrm{L}^{*}\right)$ and the highest redness (a*) (Table 3). This is attributed to the lower MC of these apple slices, although some studies reported that higher $\mathrm{a}^{*}$ is also related with the Maillard reaction, caramelization or pigment degradation [5].

These samples also showed the lowest Max. Force, which can be related to their lower MC. The lowest values were observed in samples from process 2 , which also have the lowest porosity.

Several studies reported that the higher porosity requires greater compressive strength to fracture samples [15].

Table 3. Instrumental colour and instrumental texture parameters of the apple snack samples

\begin{tabular}{cccccc}
\hline \multirow{2}{*}{ Colour parameter } & \multirow{2}{*}{ RMSE } & \multicolumn{4}{c}{ Process } \\
\cline { 3 - 6 } & & 1 & 2 & 3 & 4 \\
\hline L $^{*}$ & 3.044 & $74.75^{\mathrm{b}}$ & $74.52^{\mathrm{b}}$ & $80.47^{\mathrm{a}}$ & $76.62^{\mathrm{ab}}$ \\
$\mathrm{a}^{*}$ & 1.494 & $6.23^{\mathrm{a}}$ & $4.37^{\mathrm{a}}$ & $2.16^{\mathrm{b}}$ & $2.16^{\mathrm{b}}$ \\
$\mathrm{b}^{*}$ & 2.180 & 33.47 & 32.71 & 32.41 & 34.07 \\
Max.Force(N) & 1.909 & $5.40^{\mathrm{ab}}$ & $3.52^{\mathrm{b}}$ & $7.43^{\mathrm{a}}$ & $6.74^{\mathrm{a}}$ \\
\hline
\end{tabular}

${ }^{\mathrm{a} b}$ Means without a common superscript in a row are significantly different $(\mathrm{p}<0.05)$; RMSE: Root mean standard error; Process 1: MW(7.5 min at $3000 \mathrm{~W})+\mathrm{C}$; Process 2: MW $(3.75 \mathrm{~min}$ at $6000 \mathrm{~W})+\mathrm{C}$; Process 3: C + MW (7.5 min at $3000 \mathrm{~W})$; Process 4: C + MW (3.75 min at $6000 \mathrm{~W})$.

\section{Sensory Analysis}

Regarding appearance attributes, no significant differences were observed (results not shown). This fact indicates that, in spite of the differences observed in $\mathrm{L}^{*}$ and $\mathrm{a}^{*}$ parameters, these were not noticeable by the panelists. Similarly, no significant differences regarding taste/flavour attributes were observed (results not shown). However, samples obtained by process 1 showed a tendency to be scored with a high intensity of apple flavour, which is a desirable attribute.

Processing (MW/C or C/MW) significantly affected dried grass odour, crispiness and easiness to chew of the apple slices (Table 4). Samples obtained in process 1 (MW at the 1st drying stage and low power ratio), tended to be more crispy and more easy to chew. Differences are attributed to its lower MC and higher porosity. Samples of process 2 had lower porosity and these of processes 3 and 4 had higher MC. Other authors reported the effect of MC and porosity on crispiness and chewiness in the same direction $[16,17]$.

Regarding dried grass odour, results showed that samples obtained with processes with higher power ( 2 and 4 ) were scored with higher intensity. This effect should be taken into account because this is an attribute not desirable for an apple snack. 
Overall sensory quality showed a tendency to be higher in samples of process 1 . This result could be explained by the fact that these samples were scored with higher intensity of apple flavour, crispiness and easiness to chew and with lower intensity of dried grass odour.

Table 4. Sensory attributes

\begin{tabular}{cccccc}
\hline \multirow{2}{*}{ Attribute } & \multirow{2}{*}{ RMSE } & \multicolumn{4}{c}{ Process } \\
\cline { 3 - 6 } & & 1 & 2 & 3 & 4 \\
\hline Dried grass odour & 1.10 & $1.3^{\mathrm{b}}$ & $2.8^{\mathrm{ab}}$ & $1.1^{\mathrm{b}}$ & $3.3^{\mathrm{a}}$ \\
Crispiness & 1.81 & $7.0^{\mathrm{a}}$ & $4.8^{\mathrm{ab}}$ & $3.5^{\mathrm{b}}$ & $4.8^{\mathrm{ab}}$ \\
Easiness to chew & 1.49 & $6.3^{\mathrm{a}}$ & $3.8^{\mathrm{b}}$ & $3.5^{\mathrm{b}}$ & $3.5^{\mathrm{b}}$ \\
Overall sensory quality & 1.60 & 6.8 & 4.3 & 4.8 & 4.8 \\
\hline
\end{tabular}

${ }^{\mathrm{a}} \mathrm{b}$ Means without a common superscript in a row are significantly different $(\mathrm{p}<0.05)$; RMSE: Root mean standard error; Process 1: MW(7.5 min at $3000 \mathrm{~W})+\mathrm{C}$; Process 2: MW(3.75 min at $6000 \mathrm{~W})+\mathrm{C}$; Process 3: C + MW (7.5 min at $3000 \mathrm{~W})$; Process 4: C + MW (3.75 min at 6000W).

\section{Conclusion}

The application time of MW treatment in the apple snack process affects their physicochemical parameters and sensory attributes. The MW treatment ( $7.5 \mathrm{mint}$ at $3000 \mathrm{~W}$ ) applied at the 1st stage of drying followed by convenctive drying results in more porous apple slices and with better sensory attributes.

\section{References}

[1] Timoumi,S.;Mihoubi,D;Zagrouba,F. Shrinkage, vitamin C degradation and aroma losses during infra-red drying of apple slices. LWT-Food Science and Technology 2007,40(9),1648-1654.

[2] Bi,J.;Wang,X.;Chen,Q.;Liu,X.;Wang,Q.;Lv,J.;Yang,A. Evaluation indicators of puffing Fuji apple chips quality from diffent Chinese origins. LWT-Food Science and Technology 2015,60(2),1129-1135.

[3] Contreras,C.;Martin,M.E.;Martinez-Navarrete,N.;Chiralt,A. Effect of vacuum impregnation and microwave application on structural changes which occurred during air-drying of apple. LWT-Food Science and Technology2005,38(5),471-477.

[4] Schulze,B.;Hubbermann,E.M.;Schwarz,K. Stability of quercetin derivatives in vacuum impregnated apple after drying(microwave vacuum drying, air drying, freeze drying) and storage. LWT-Food Science and Technology 2014,57(1),426-433.

[5] Velickova,E.;Winkelhausen,E.;Kuzmanova,S. Physical and sensory properties of ready to eat apple chips produced by osmo-convective drying. Journal of Food Science and Technology 2014,51(12),3691-3701.

[6] Chandrasekaran,S.;Ramanathan,S.;Basak,T. Microwave food processing-A review. 
Food Research International 52 (2013),243-261.

[7] Zhang,M.;Tang,J.;Mujumdar,A.S.;Wang,S. Trends in microwave-related drying of fruits and vegetables. Trends Food Sci Technol 2006,17(10):524-534.

[8] Askari,GR.;Emam-Djomeh,Z.;Mousavi,S.M. Effects of combined coating and microwave assisted hot-air drying on the texture, microstructure and rehydration characteristics of apple slices. Food Sci Technol Int 2006,23(1):39-46.

[9] Argyropoulos,D.;Heindl,A.;Müller,J. Assessment of convection, hot-air combined with microwave-vacuum and freeze-drying methods for mushrooms with regard to product quality. Int J Food Sci Technol 2011,46(2),333-342.

[10] Qiu,J.;, Khalloufi,S.; Martynenko,A.; Van Dalen,G.; Schutyser,M.; Rivera,C.A. Porosity, Bulk Density, and Volume Reduction During Drying: Review of Measurement Methods and Coefficient Determinations, Drying Technology 2015, 33:14, 1681-1699.

[11] Joardder,M.U.H.;Kumar,C.;Brown,R.J.;Karim,M.A. A micro-level investigation of the solid displacement method for porosity determination of dried food.Journal of Food Engineering 166(2015) 156-164.

[12] American Society for Testing and Materials (1981) Guidelines for the selection and training of sensor and panel members. In STP 758 Philadelphia: ASTM

[13] Amerine M, Pangborn R, Roessler E (1965) Principles of sensory evaluation of food. Academic Press, New York.

[14] Rahman,M.S.,Al-Zakwani,I.,Guizani,N. Pore formation in Apple during air-drying as a function of temperatura: Porosity and pore-size distribution. Journal of the Science and Agriculture, 2005, 6(85), 979-989.

[15] Anton A.A.; Luciano F.B.; Instrumental texture evaluation of extruded snack foods: A review Evaluacion instrumental de textura en alimentos extruidos:Una revision. Journal of food, 2007,5:4,245-251.

[16] Zbigniew, Ranachowski \& Marzec, Agata.Acoustic properties of foods,2008.

[17] Tsukakoshi,Y, Naito,S., and Ishida,N. Fracture intermittency during a puncture test of cereal snacks and its relation to porous structure. Food Res. Int, 2008, 1, 909-917. 